\title{
Effect of chemical and sanitary intervention on rat sightings in urban communities of New Providence, the Bahamas
}

\author{
Adedayo M. Awoniyi ${ }^{1} \cdot$ Andrew Thompson $^{2} \cdot$ Luther Ferguson $^{2} \cdot$ Melony Mckenzie $^{2} \cdot$ Fabio N. Souza $^{1}$. \\ Caio G. Zeppelini ${ }^{1} \cdot$ Federico Costa $13,4,5,6$
}

Received: 26 October 2020 / Accepted: 1 March 2021 / Published online: 24 March 2021

(c) The Author(s) $2021 \quad$ OPEN

\begin{abstract}
Rats are invasive pest species that commonly infest low-income urban environments. Their association with humans constitutes a threat of rodent-borne disease transmission. We evaluated the outcome of a chemical and sanitary intervention on rat sightings in seven low-income urban settlements of New Providence, the Bahamas. The intervention consisted of rodenticide application, education about environmental sanitation, and improvement in waste disposal. Rat sightings were systematically recorded by trained staff before and three months after the intervention. The intervention slightly decreased rat sightings, with an average of 2.7-fold with varied effectiveness across locations. Four out of seven locations (57\%) registered a decrease in rat sightings. Our results suggest that social and environmental differences among communities may be responsible for the mixed efficacy observed in the current rodent management practice in urban communities of the Bahamas. However, a new set of control measures needs to be developed for areas where rodent decline was not observed. This study provides novel data on how rat population behaves post-intervention in a unique ecological setting like the Bahamas, presenting an informed judgment for their management, especially in the event of a natural disaster.
\end{abstract}

Keywords Rat $\cdot$ Rat sightings $\cdot$ Rodenticide $\cdot$ Rodent control $\cdot$ Urban community $\cdot$ Zoonoses

\section{Introduction}

Rats (genus Rattus) are widely distributed and successful invasive species that are present in all continents except Antarctica [1]. They were likely introduced into North America in the 1750s through trans-Atlantic navigation during the European colonization [2]. They adapt well to human-altered environments and are regarded as notorious agricultural and urban pests [3]. In urban settings, their infestation is often associated with low socioeconomic status, inefficient waste management, open sewers, overcrowding, and other infrastructure characteristics that can be exploited for food and harbourage [4].

Frequent rat sightings have been reported as an indicator of poor sanitation and diseases [5]. Rats are famous reservoirs of several infectious diseases (e.g.

Adedayo M. Awoniyi and Andrew Thompson have contributed equally to this work.

Supplementary Information The online version contains supplementary material available at https://doi.org/10.1007/s42452-02104459-x.

Federico Costa, fcosta2001@gmail.com | 'Instituto de Biologia, Universidade Federal da Bahia, Salvador, BA 40170-115, Brasil. ${ }^{2}$ Department of Environmental Health Services (DEHS), Ministry of Environment and Housing, Government of the Bahamas, Nassau, Bahamas. ${ }^{3}$ Instituto de Saúde Coletiva, Universidade Federal da Bahia, Salvador, BA 40110-040, Brasil. ${ }^{4}$ Centro de Pesquisas Gonçalo Moniz, Fundação Oswaldo Cruz, Salvador, BA, Brasil. ${ }^{5}$ Department of Epidemiology of Microbial Diseases, Yale School of Public Health, New Haven, CT 06511, USA. ${ }^{6}$ Lancaster Medical School, Lancaster University, Lancaster LA1 4YW, UK. 
leptospirosis, toxoplasmosis, lassa fever, and other viral hemorrhagic fevers) and play important role in their transmission to humans [6-8]. Besides their health implication, their presence in the islands has led to the destabilization of the ecosystem, competition, and extinction of local fauna [9], in conjunction with the destruction of agricultural produce and household properties worth billions of dollars [10].

The main strategies used for controlling rat infestations have been application of chemical rodenticides [6], environmental modification [11] and physical population removal [12]. However, most of these control efforts have yielded limited effectiveness [13], with the added possibility of negative impacts on zoonoses prevalence [14]. Advances are hindered due to the trade-off between techniques. Physical removal is labour and resource-intensive, and environmental management is labour-intensive and depends on ecological know-how. Chemical control has an easy application but allows population rebound if resources are available and can act as a selective pressure for neophobia and poison resistance among the remaining population $[3,6]$. Thus, an effective rodent control program demands evidence-based planning and a multi-scale approach.

Despite the increasing labour force in the Bahamas, the national unemployment rate remains somewhat high (16\%) and even higher among the youth (30\%), thereby forcing residents to live below the poverty line [15]. In urban communities of New Providence, most of the population live in overcrowded apartments with poorly constructed privies, improper sewage, and waste management system [16], thereby providing conditions that encourage human-rat cohabitation [4].

Therefore, given the ecological and geographical composition of the Bahamas and its projected sea-level rise and floodings [17], there are growing concerns about possible rat proliferation and probable rodent-borne disease outbreak in the country. This is justifiable considering the likelihood of a rodent-borne disease outbreak following a natural disaster [18]. Previous studies have shown that natural disasters may change the mortality and spatial distribution patterns of rodents and consequent increase in pathogen prevalence [19]. Therefore, it is critical to evaluate whether the ongoing integrated rat management program is effective against probable rat population explosion, especially in the event of natural disaster in the Bahamas. It is based on this that we report our observation of the short-term effect (11 weeks, approximately three months) of a chemical and sanitary intervention hereinafter referred to as "intervention" on rat sightings in selected locations of New Providence, the Bahamas.

\section{Materials and methods}

\subsection{Study site}

The study was carried out in low-income settlements of New Providence Island, the Bahamas. New Providence is located between Andros Island (West) and Eleuthera Island (East) with Latitude N25 04' 00" and Longitude W $7721^{\prime} 00^{\prime \prime}$. It is a principal island in the Bahamas, majorly of woody vegetation, consisting of shrubs and low trees, with an area of $80 \mathrm{sq} \mathrm{mi}$ and a population of 246,329 [20]. Seven settlements tagged locations "A, B, C, D, E, $\mathrm{F}$ and $\mathrm{G}^{\prime \prime}$ (Fig. 1) with a record of regular rat sightings were used. Locations were selected as part of a local program to improve those communities including a transformation and restoration of the area performed in phases. Rodent control described here was one of the initial phases of the program. Each location contains a minimum of 10 blocks, with 5 premises (mostly wooden houses) per block. The locations are interspersed with small businesses and possess environmental/sanitation conditions that could impact rodent intervention efforts, e.g. derelict vehicles, garbage accumulation (both regular and discarded materials like furniture), abandoned or unfinished constructions and overgrown properties. Refuse collection in some of the locations is partially satisfactory with limited bulk waste collection in most of the sites.

\subsection{Study design}

\subsubsection{Intervention}

We applied an anticoagulant rodenticide (brodifacoum) to infested households, conducted education about environmental sanitation (i.e. enlightened the heads of households, and shop owners about the importance of appropriate waste disposal; putting waste out at collection point on the morning/evening of collection instead of days before collection; keeping pets' food out of reach of rats, and the need to reduce or obstruct other sanitation-related means by which rats could gain access to food and or water) and where applicable damaged/ missing trash cans were replaced by the Bahamas Ministry of Environment and Housing. The intervention was performed from 3 May 2019 to 23 May 2019. Before the commencement of baiting, we clearly explained the purpose of the intervention to the residents and enlightened them about the importance of practicing appropriate waste disposal. Using the US' Center for Disease Control and Prevention (CDC) [21] guidelines for interior 
Fig. 1 Description of the study locations in low-income communities of New Providence, the Bahamas
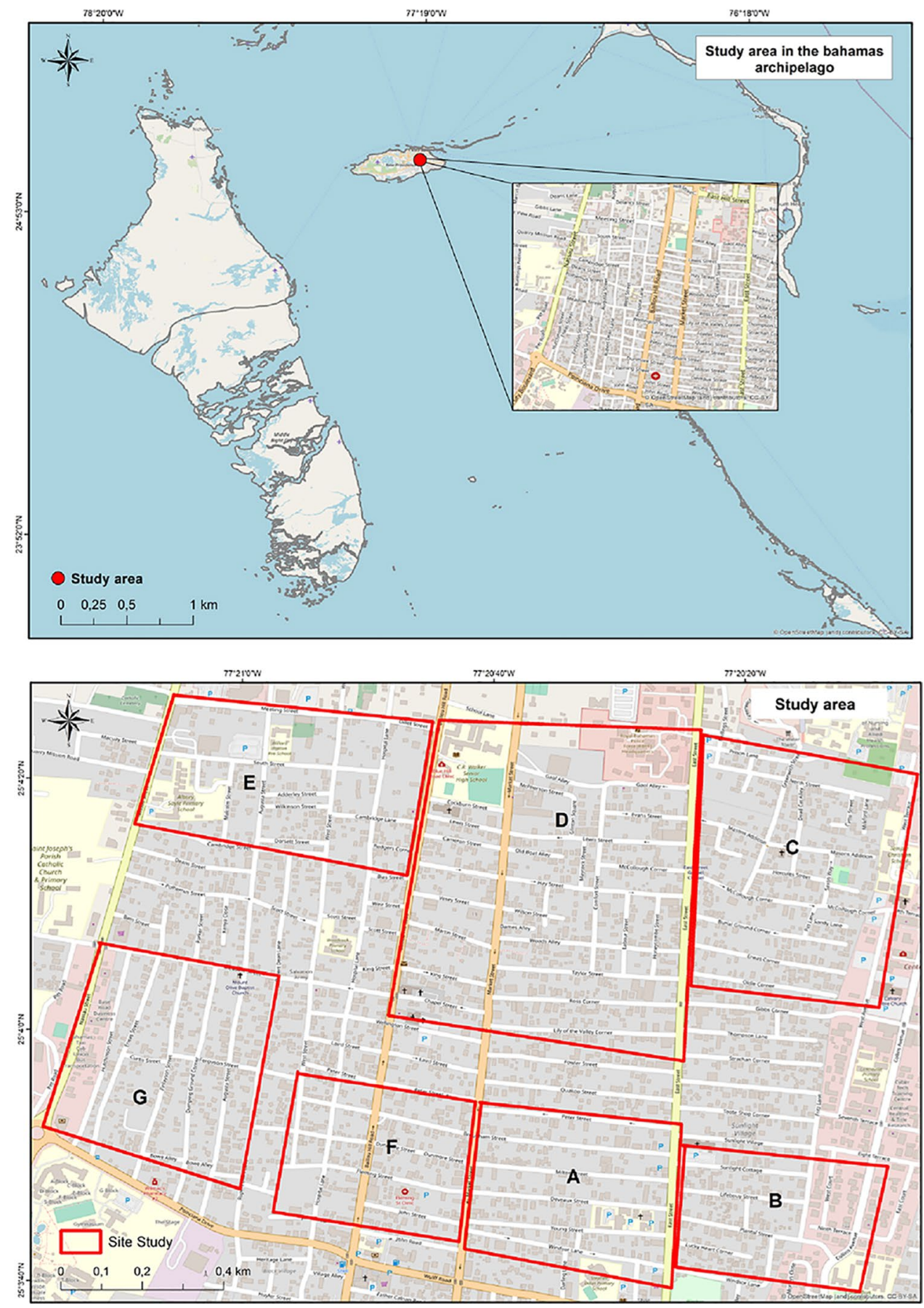

and exterior rodent inspection form, we identified spots suitable for rat baiting at infested properties and areas around the properties in the study locations.

\subsubsection{Baiting}

We applied brodifacoum-tracking powder to either identified infested properties or areas around the properties following the manufacturer's instructions of placing bait stations in areas with active rodent signs, accessible only to rodents and not to other non-target species. Two bait stations of full holding capacity were placed at each block, visited, and replaced once a week for three consecutive weeks.

\subsubsection{Evaluation}

We slightly modified the method previously used by Promkerd et al. [22] and Walsh [23] to evaluate rat sightings before and three months after the intervention. Rat 
sightings were recorded in a survey form (Supplementary material 1) over the period of $4 \mathrm{~h}$ (3-hrs 20-mins stationary observation, and 40-mins slow-movement observation through previously defined circuits) per day by 2 to 3 trained personnel stationed at each location for three consecutive days. Recordings were done from 7 to $11 \mathrm{pm}$ - being the period when rats are most active, except in situations where there is minimal disturbance during the day, subordinate rats trying to avoid dominant individuals or rats trying to avoid predation [21, 24]. The pre-intervention evaluation was done between 30 April 2019 and 2 May 2019, and post-intervention between 17 July 2019 and 19 July 2019, respectively.

\subsubsection{Statistical analysis}

Comparisons of rat sightings among locations before and after intervention were statistically analysed using a paired samples Wilcoxon test with a significance level of 0.05 . Also, we ran a generalized linear mixed models (GLMMs) with Poisson error distribution (log link function) using the Lme4 package to investigate the effect of the intervention with the location as a random factor. All analyses were performed in R 3.6.1 version [25].

\section{Results}

With the surveys, we found a noticeable rodent activity across all locations before the intervention, with locations $C$ and $D$ having the highest rat sightings and locations $B$
Fig. 2 Frequency distribution of rat sightings before and after intervention in lowincome communities of New Providence Island, the Bahamas. a Rat sightings before and after intervention by locations in New Providence. b Overall distribution of rat sightings before and after intervention in New Providence
Table 1 Variations in rat sightings before and after intervention in urban communities of New Providence Island, the Bahamas

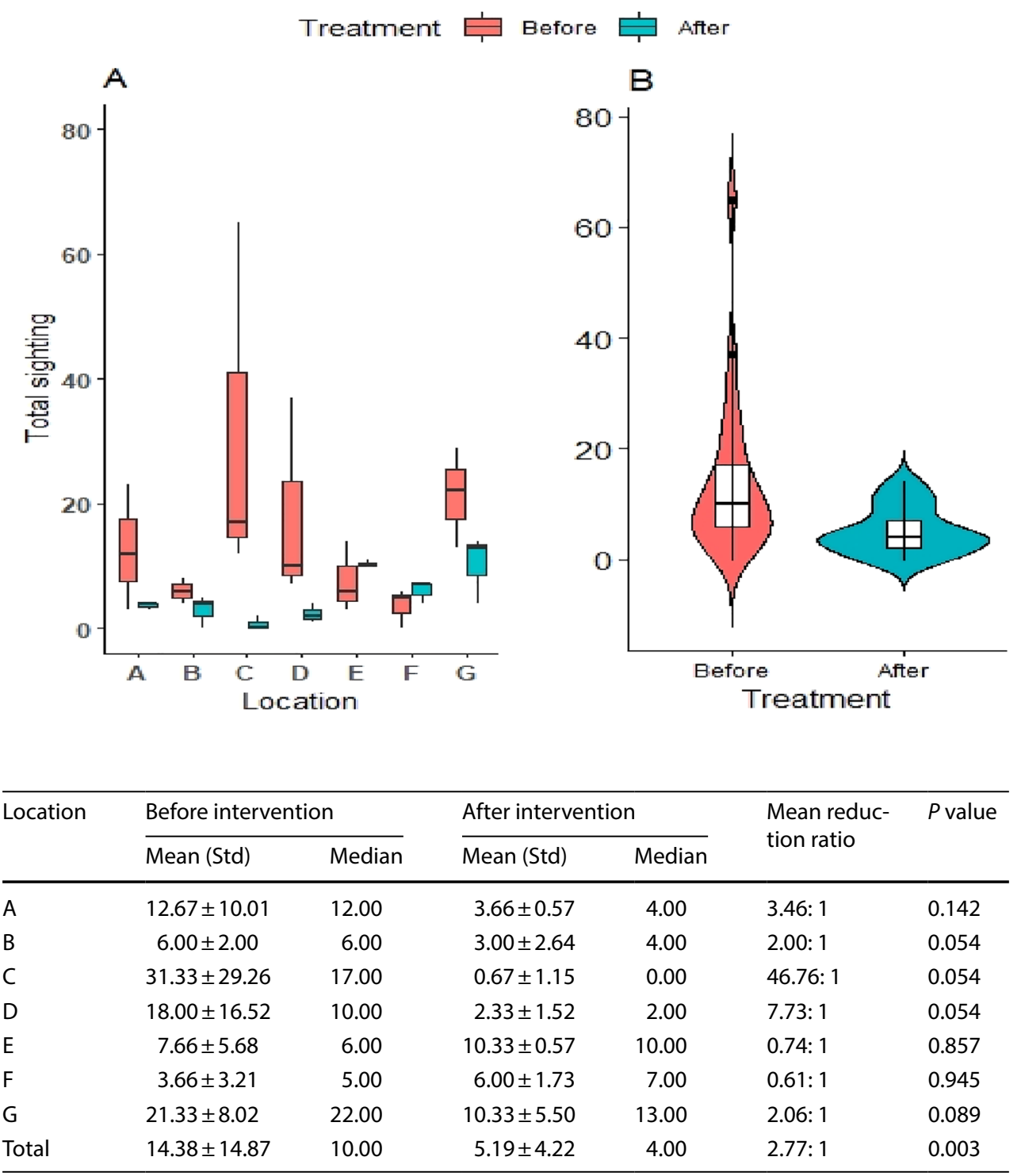


Table 2 Summary of rat sightings before and after intervention in urban communities of New Providence Island, the Bahamas

\begin{tabular}{|c|c|c|c|}
\hline \multicolumn{4}{|l|}{ Rat sightings } \\
\hline Predictors & Estimates & $\mathrm{Cl}$ & $p$ \\
\hline (Intercept) & 14.38 & $9.61-19.15$ & $<0.001$ \\
\hline Before intervention & Reference & & \\
\hline After intervention & -9.19 & -15.75 to -2.63 & 0.006 \\
\hline
\end{tabular}

and $\mathrm{F}$ with the lowest sightings (Fig. 2a). There was an apparent disparity in rat sightings before and after the intervention (Fig. 2b), with a mean reduction ratio ranging from 0.61 to 46.76 (Table 1). At locations A, B, C, D, and $G$, the mean rat sightings decreased after intervention but increased at locations E and F (Fig. 2a). Overall, the intervention had a negative effect on the number of rat sightings after intervention as compared to before intervention, with an average reduction of 9 rats in the number of rat sightings (Table 2 ) and a varied level of effectiveness noticed across the sampling locations (Table 1). The paired samples Wilcoxon test illustrated a significant overall mean reduction ratio $(2.77: 1, P=0.003)$, with a non-significant reduction in the mean values of rat sightings at location $A$, $B, C, D$, and $G$ after the intervention, respectively (Table 1 ). On the other hand, at locations $E$ and $F$, a non-significant increase in the mean values of rat sightings was reported after the intervention (Table 1).

\section{Discussion}

The intervention caused on average a 2.7-fold overall significant decrease in rat sightings with a mean reduction ranging from 0.61 to 46.71 amid variations in effectiveness among sampling locations. The high rat sightings before intervention are not surprising, given the availability of factors that support the proliferation of rats in the study locations. Therefore, these high rat sightings may be associated with the residents' socioeconomic conditions, with most of them living in impoverished conditions [26]. The differences in the effectiveness of the intervention across locations and the broad margin in the mean reduction ratio in rat sightings may be due to differences in features and management practices among these locations.

The reduction in rat sightings (although non-significant) noticed after intervention at four out of the seven locations suggests that socio-environmental attributes (specifically education level and fair waste management) in these locations are suitable for the type of intervention currently employed in the communities. However, the lower number of rat sightings recorded at locations $E$ and $F$ before the intervention may account for the non-significant increase noticed after the intervention. Likewise, the non-significant decrease in rodent sightings at location $A$ might be due to the lower socio-environmental conditions of the residents, i.e. poor standard of living, waste management and education level (data not shown), which may provide extra nourishments, thus limiting the effectiveness of the intervention [27].

Knowing that rat population may peak shortly after a brief decline immediately after natural disasters [28], and given the ecological setting of New Providence, an island with shallow and warm water that is prone to hurricanes and flooding. It would be impracticable to clean up waste in the event of natural disaster, thus bringing about conditions that are favourable to rodent proliferation and probable pathogen prevalence $[29,30]$. Hence, it is critical to evaluate local strategies used for regular rodent control that can potentially be used to deal with the potential rat population increase in the event of natural disasters.

Therefore, although the effectiveness of the intervention differs across the study locations, our result suggests that it provides an immediate means of controlling the rat population in most of the communities, especially those with modest socio-economic status. This outcome will potentially be helpful in this unique ecological setting likewise other Caribbean countries during natural disasters. However, it would be necessary to develop a new set of control measures for areas where rodent decline was not observed. Additionally, if a long-term management plan is to be guaranteed, it would be indispensable to conduct a longer-span study to better understand how rodent populations behave at longer timespans (six months to one year after intervention).

Acknowledgements We thank the Government of the Bahamas and residents of the study locations for their cooperation during the study.

Funding This work was partly supported by the National Council for Scientific and Technological Development-CNPq and the Environmental Health Advisor for the Bahamas Hurricane Dorian Response-DEHS, the Bahamas. AMA was a CNPq-TWAS Ph.D. fellow, while FNS and CGZ were FAPESB Ph.D. fellows at the time of this study.

Availability of data and code The datasets and codes used during the current study are available from the corresponding authors on reasonable request.

\section{Declarations}

Conflict of interest The authors declare that they have no conflict of interest.

Open Access This article is licensed under a Creative Commons Attribution 4.0 International License, which permits use, sharing, adaptation, distribution and reproduction in any medium or format, as long as you give appropriate credit to the original author(s) and the source, provide a link to the Creative Commons licence, and indicate 
if changes were made. The images or other third party material in this article are included in the article's Creative Commons licence, unless indicated otherwise in a credit line to the material. If material is not included in the article's Creative Commons licence and your intended use is not permitted by statutory regulation or exceeds the permitted use, you will need to obtain permission directly from the copyright holder. To view a copy of this licence, visit http://creativecommons. org/licenses/by/4.0/.

\section{References}

1. Morand S, Bordes F, Chen HW et al (2015) Global parasite and Rattus rodent invasions: The consequences for rodent-borne diseases. Integr Zool 10(5):409-423. https://doi.org/10.1111/ 1749-4877.12143

2. Puckett EE, Park J, Combs M et al (2016) Global population divergence and admixture of the brown rat (Rattus norvegicus). Proc Biol Sci 283:20161742. https://doi.org/10.1098/rspb.2016.1762

3. Parsons MH, Banks PB, Deutsch MA et al (2017) Trends in urban rat ecology: a framework to define the prevailing knowledge gaps and incentives for academia, pest management professionals (PMPs) and public health agencies to participate. J Urban Ecol 3(1):1-8

4. Langton S (2001) The occurrence of commensal rodents in dwellings as revealed by the 1996 English house condition survey. J Appl Ecol 38:669-709

5. Byers KA, Cox SM, Lam R, Himsworth CG (2019) “They're always there": resident experiences of living with rats in a disadvantaged urban neighbourhood. BMC Public Health 19(1):853. https://doi.org/10.1186/s12889-019-7202-6

6. Lambert MS, Quy RJ, Smith RH, Cowan DP (2008) The effect of habitat management on home-range size and survival of rural Norway rat populations. J Appl Ecol 45:1753-1761. https://doi. org/10.1111/j.1365-2664.2008.01543.x

7. Costa F, Porter FH, Rodrigues $\mathrm{G}$ et al (2014) Infections by Leptospira interrogans, Seoul virus, and Bartonella spp. among Norway rats (Rattus norvegicus) from the urban slum environment in Brazil. Vector Borne Zoonotic Diseases 14:33-40. https://doi. org/10.1089/vbz.2013.1378

8. Battersby S (2015) Rodents as carriers of diseases. In: Buckle A, Smith R (eds) Rodent pests and their control, 2nd edn. CABI International, Wallingford, pp 81-101

9. Higgins TW, Bridges AS, Sanchez JN (2015) Spatial ecology of invasive black rats (Rattus rattus) on San Clemente Island, California. Southwestern Naturalist 60(2-3):186-192

10. Childs JE, Glass GE, Le Duc JW (1991) Rodent sightings and contacts in an inner-city population of Baltimore, Maryland, USA. Bull Soc Ecol 16:245-255

11. Lawrence MS (2002) Roof rat control around homes and other structures. Extension Wildlife Damage Management Specialist. The University of Arizona, College of Agriculture and Life Sciences Tucson, Arizona 85721

12. Pascal M, Siorat F, Lorvelec O, Yéson P, Simberloff D (2005) A pleasing consequence of Norway rat eradication: two shrew species recover. Divers Distrib 11:193-198. https://doi.org/10. 1111/j.1366-9516.2005.00137.x

13. Oyedele DT, Sah SAM, Kairuddin L, Ibrahim WMMW (2015) Range measurement and a habitat suitability map for the Norway rat in a highly developed urban environment. Trop Life Sci Res 26(2):27-44

14. Byers KA, Lee MJ, Patrick DM, Himsworth CG (2019) Rats about town: a systematic review of rat movement in urban ecosystems. Front Ecol Environ 7(13):1-12. https://doi.org/10.3389/ fevo.2019.00013

15. National Development Plan Secretariat Bahamas (2016) State of the Nation report: Vision 2040- National Development Plan of The Bahamas. Nassau: NDPS; 2016. Available on: http://www. vision2040bahamas.org/media/uploads/State_of_the_Nation Summary_Report.pdf. Accessed 15 Oct 2020

16. Department of Statistics, Census Section Bahamas (2014) Socioeconomic report 2008-2012. Nassau: DOS. Available on: https:// www.bahamas.gov.bs/wps/wcm/connect/d5899539-d31b4234-af37-88a3cbf8dbe5/Socio-Economic+Report+2008-2012. pdf?MOD=AJPERES. Accessed 15 Oct 2020

17. Strauss B, Kulp S (2018) Sea-Level Rise Threats in the Caribbean: Data, tools, and analysis for a more resilient future. (February), 1-25. Retrieved from http://sealevel.climatecentral.org/uploa ds/ssrf/Sea-level-rise-threats-in-the-Caribbean.pdf

18. Patz JA, Olson SH, Uejio CK, Gibbs HK (2008) Disease emergence from global climate and land use change. Med Clin N Am 92(6):1473-1491. https://doi.org/10.1016/j.mcna.2008.07.007

19. Long JL (2003) Introduced Mammals of the World: their History, Distribution and Abundance. CSIRO Publishing, Collingwood, Victoria, Australia, and CABI Publishing, Wallingford, United Kingdom. xxi + 589 pp. ISBN 0-643-06714-0

20. Britannica (2018) New Providence Island, Island, The Bahamas, Geography and Travel, Physical Geography of Land, Island and Archipelagos. https://www.britannica.com/place/New-Provi dence-Island, Accessed 23 Sept 2020.

21. CDC (2006) Integrated pest management: conducting urban rodent surveys. US Department of Health and Human Services, Centers for Disease Control and Prevention- Atlanta

22. Promkerd $P$, Khoprasert $Y$, Virathavone $P$ et al (2008) Factors explaining the abundance of rodents in the city of Luang Prabang, Lao PDR, as revealed by field and household surveys. Integr Zool 3(1):11-20. https://doi.org/10.1111/j.1749-4877. 2008.00069.x

23. Walsh GM (2014) Rat sightings in New York City are associated with neighborhood sociodemographics, housing characteristics, and proximity to open public space. PeerJ 2:e533

24. Michael GPF, David WM (1995) Use of middens by red foxes: risk reverses rhythms of rats. J Mammal 76(1):130136. https://doi. org/10.2307/1382321

25. R Core Team (2019) R: A language and environment for statistical computing. R Foundation for Statistical Computing, Vienna, Austria. URL https://www.R-project.org

26. Masi E, Vilaça P, Razzolini MTP (2009) Environmental conditions and rodent infestation in Campo Limpo district, São Paulo municipality, Brazil. Int J Health Res 19(1):1-16. https://doi.org/ 10.1080/09603120802126670

27. Masi E, Pino FA, das Santos GSM et al (2010) Socioeconomic and environmental risk factors for urban rodent infestation in Sao Paulo, Brazil. J Pest Sci 83(3):231-241. https://doi.org/10.1007/ s10340-010-0290-9

28. Peterson AC, Ghersi BM, Campanella R et al (2020) Rodent structure reflects socioecological mosaics of counter-urbanization across post-Hurricane Katrina New Orleans. Landscape and Urban Plan 195:103710

29. Barcellos C, Sabroza P (2001) The place behind the case: leptospirosis risks and associated environmental conditions in a flood-related outbreak in Rio de Janeiro. Cadernos de Saude Publica 17(Suppl.):59-67. https://doi.org/10.1590/S0102-311X2 001000700014

30. Enscore RE, Biggerstaff BJ, Brown TL et al (2002) Modeling relationships between climate and the frequency of human plague cases in the southwestern United States, 1960-1997. Am JTrop Med Hyg 66:186-196. https://doi.org/10.4269/ajtmh.2002.66.186

Publisher's Note Springer Nature remains neutral with regard to jurisdictional claims in published maps and institutional affiliations. 